\title{
Short-term effect of stock volatility and cardiovascular mortality: a systematic review and meta-analysis
}

\author{
Hui Lian ${ }^{1 \#}$, Xin Ding ${ }^{2 \#}$, Hongmin Zhang ${ }^{2}$, Xiaoting Wang ${ }^{1,2}$ \\ ${ }^{1}$ Health Care Department, Peking Union Medical College Hospital, Beijing, China; ${ }^{2}$ Critical Care Department, Peking Union Medical College \\ Hospital, Beijing, China \\ Contributions: (I) Conception and design: H Lian; (II) Administrative support: X Wang; (III) Provision of study materials or patients: H Lian, X Ding; \\ (IV) Collection and assembly of data: H Lian, X Ding; (V) Data analysis and interpretation: H Lian, X Wang; (VI) Manuscript writing: All authors; \\ (VII) Final approval of manuscript: All authors. \\ "These authors contributed equally to this work. \\ Correspondence to: Xiaoting Wang, MD. Department of Health Care and Department of Critical Care Medicine, Peking Union Medical \\ College Hospital, Chinese Academy of Medical Sciences, No. 1 Shuaifuyuan, Wangfujing, Dongcheng District, Beijing 100730, China. \\ Email: wangxiaoting@pumch.cn.
}

\begin{abstract}
Background: Cardiovascular disease (CVD) and stroke are leading causes of death. It has several risk factors, including stress and pressure. Stock volatility can cause acute stress for stockholders so that it can cause CVD events. Recently, the spread of new coronaviruses worldwide has affected economic development greatly, leading to more severe stock market fluctuations, so we systematically quantify the short-term effect of stock volatility and CVD events.
\end{abstract}

Methods: Time-series analysis on the effect of stock volatility and cardiovascular events were concluded. We conducted a systematic literature search for studies published in PubMed, Embase, and Cochrane Data up to the date February 9, 2020. We assessed publication bias using Egger's test. Overall analysis and sensitivity analysis were conducted separately.

Results: Four studies were finally included. Every 100-point increase in the stock market will bring about $1.01 \%$ increases in cardiovascular mortality [95\% confidence intervals (CI), $-0.18 \%$ to $2.21 \%$ ]. The metaanalysis showed no statistical significance for cardiovascular mortality. Every 100-point increase in the stock market brought $1.01 \%$ increases in the cardiovascular mortality [ $95 \% \mathrm{CI},-0.18 \%$ to $2.21 \%$ ]. In terms of stroke events, the estimated effect was $2.999 \%$ (95\% CI, $0.325 \%$ to $5.673 \%$ ). Different lag patterns also have effects on cardiovascular mortality. Every 100-point increase brought about $4.026 \%$ (95\% CI, $1.516 \%$ to $6.536 \%$ ) and $4.424 \%$ (95\% CI, $1.145 \%$ to $7.703 \%$ ) for lag 01 and 04 separately.

Conclusions: Though our study has a number of limitations due to the limited studies included, it suggested that stock volatility had a lagging effect on CVD mortality, which may last for several days. Also, it might increase the incidence of stroke.

Keywords: Stock volatility; cardiovascular mortality; stroke; meta-analysis

Submitted Aug 25, 2020. Accepted for publication Oct 10, 2020.

doi: $10.21037 / \mathrm{atm}-20-6557$

View this article at: http://dx.doi.org/10.21037/atm-20-6557

\section{Introduction}

Cardiovascular disease (CVD) and stroke are leading causes of death. According to the American Heart Association, CVD accounted for an estimated 31.5\% [95\% confidence intervals (CI), 30.3-32.9\%] of all global deaths in 2013 in the world (1). With population growth and aging, various CVD deaths had an increase of $41 \%$ from 1990 to 2013 (12.3 million to 17.3 million) (2). From the statistics performed by WHO, the global cost of CVD was estimated at the US $\$ 863$ billion (3). Except for the well-established traditional risk 
factors, psychosocial factors and emotional stressors could also harm cardiovascular health (4). So, it is easily understood that a considerable fluctuation in the stock market and financial difficulties may bring substantial psychosocial stresses. Previously, stock volatility had been suggested as a potential risk factor of coronary heart disease (CHD) (5). Because it could cause acute stress, stock volatility could adversely affect CVD. Moreover, the recent spread of new coronaviruses worldwide has affected economic development, which has led to more severe stock market fluctuations.

Few studies paid attention to the impact of unprecedented growth and collapse in the stock market on the health effect (5). Both linear and non-linear relationships have been reported. The non-linear relationship suggested that for many fluctuations, the mortality rate stayed low, below or above which the health outcome increased. However, not all the studies discovered a positive relationship. Therefore, we conducted a systematic meta-analysis to investigate the association between stock volatility and the risk of cardiovascular mortality. We present the following article in accordance with the PRISMA reporting checklist (available at http://dx.doi.org/10.21037/atm-20-6557).

\section{Methods}

\section{Search strategy and study criteria}

We conducted a systematic literature search for studies published in PubMed, Embase, and Cochrane Data up to the date February 9, 2020. Keywords related to exposure (stocks and volatility) and outcome (CVD, mortality) were used. Mesh methods were used to ensure accuracy. For example, the search strategy for PubMed was ("stock volatility"[Mesh] AND “mortality"[Mesh]). We also retrieved studies from the references in case that the first search did not capture studies.

We included time-series studies that reported cardiovascular mortality and all-cause mortality, and other morbidities in response to stock market volatility. Commentaries, summaries, reviews, case reports, case series, editorials, letters were excluded. In the case of the missing data-without relative risk (RR) or odds ratio (OR), we contacted the authors for other information. If no further information were achieved, the study would be excluded.

\section{Study choice}

All titles and abstracts were merged into Endnote, and duplicates were searched and removed. Then we screened all abstracts and titles separately (H.L. and X.D.) to remove the irrelevant citations. Full texts of the potentially eligible studies were read for inclusion. The two reviewers then compared the results. If different opinions appeared, the first step was to discuss them to reach a consensus. If no agreement were reached after discussion, arbitration was sought from a third reviewer (X.W.). The third reviewer decides whether to delete the article based on whether the structure of the article meets the requirements of meta analysis and whether the effect value can be applied or applied after transformation.

\section{Quality assessment}

According to the Cochrane Handbook (6), and other related studies and articles $(7,8)$, we evaluated the study quality from the following aspects: study design, sample size, statistical analysis methods, stock market, adjusted confounders including meteorological factors, air pollutants, long-term trends, day of the week, and technique of disease diagnosis.

\section{Data extraction and publication bias}

Authors (H.L. and X.D.) conducted data extraction independently. After the discussion, we decided to use a standardized checklist to extract data from the selected studies. The items that we collected were: title, author(s), year of publication, location and period, outcome, published journal, study design, statistical analysis model, number of events, variables controlled for, lag patterns, and effective value. If there were any missing information, we contacted the author. The effect value could be expressed in OR, $\mathrm{RR}$ and percent change. The expression of stock volatility differed in the studies. Some used the percent change; others used 100-point change. Both were extracted. All the effective estimates including mortality and lag patterns. When data extraction was finished, we compared and crosschecked the extracted data; Prof. Wang decided conflicts. We assessed publication bias using Egger's test.

\section{Statistical analysis}

The statistical analysis included two stages. In the first stage, we unified the independent variables into 1-percent change and 100-point change. We converted all effect estimates into RRs and got the percent change. In the 


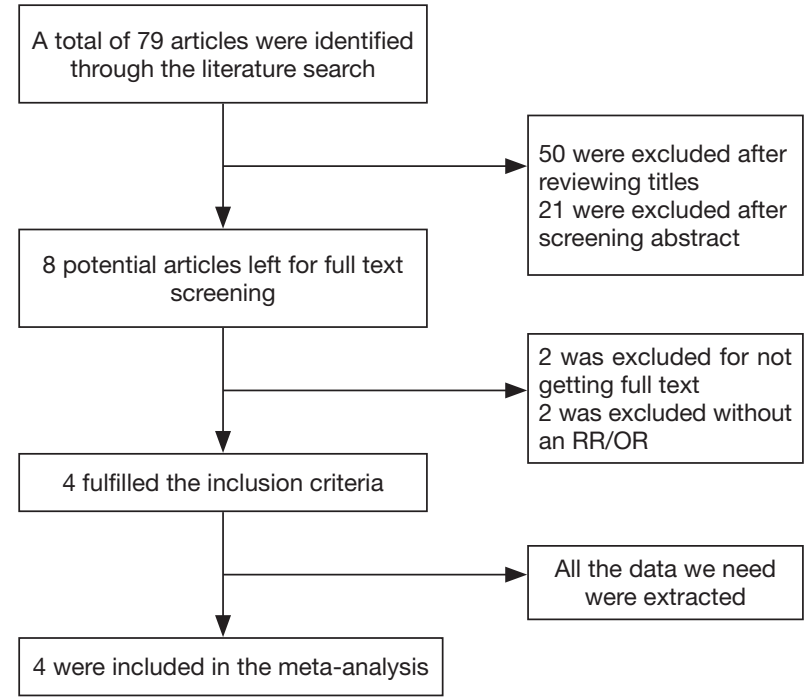

Figure 1 Flow of information through the distinct phases of a systematic review.

second stage, a meta-analysis was used to pool the estimates of percent change from all the included cities. The analyses were conducted when the number of the study was no less than two. The primary endpoints we focused on were cardiovascular mortality. As we pooled the city-specific estimates, if a city had no pooled result, we pooled the subgroup effect estimates before the final total analysis. In a few analyses, different studies conducted in the same city, but focus on different diseases. Faced with this problem, we pooled the disease-specific effect estimates first. Then we pooled city-specific estimates as a result. Several studies supplied different lag patterns of exposure to estimate the delayed effect, including single-day lag and cumulative lag. We conducted the pooled lag-patterns as the sensitivity analysis to assess certain in the outcome. The $\mathrm{I}^{2}$ statistic was calculated to evaluate the city-specific estimates. Metaanalyses were fitted using a random effects model if $\mathrm{I}^{2}>25 \%$. Otherwise, we chose the fixed effects model.

All the analyses were conducted by Excel and Stata 16.0 (Stata Corp., College Station, Texas, USA).

\section{Results}

Finally, 79 articles were included in the initial search (Figure 1). After reviewing titles and abstracts, 71 were excluded because they were unqualified for the inclusion criteria. Of the remaining eight articles, two were abandoned for no full-text articles $(9,10)$. Two were excluded for only finding a positive relationship without an RR/OR (11,12). After reviewing the full-text articles, all the remaining four studies were included in the final analysis.

The characteristics of the included articles are listed in Table 1. Four articles included four places. These were Shanghai $(5,13)$, Guangdong, Taishan (14) in China, and Singapore (15) in northeast Asia. Study periods varied from 2 to 12 years. Those were possible causes of heterogeneity among study results. All the studies were time-series designed. All the studies used a generalized linear model (GLM), and one study applied a distributed lag non-linear model (DLNM) (14). Shanghai Stock Exchange $(5,13)$, Shenzhen Stock Exchange (14), and Singapore Stock Exchange (15) were used separately. Two ways were used to calculate the stock market changes, absolute changes and relative changes. The studies explored different outcomes, including cardiovascular mortality (including stroke), admission for heart failure, stroke, and myocardial infarction. Three of them explored different lag patterns. No obvious publication bias was found after Egger's test $(\mathrm{P}=0.273)$.

The meta-analysis showed no statistical significance between stock fluctuation and cardiovascular mortality. Every 100-point increase in the stock market will bring about a $1.01 \%$ increase in cardiovascular mortality $(95 \%$ CI, $-0.18 \%$ to $2.21 \%$ ) (Figure 2). In terms of stroke events, the estimated effect would be $2.999 \%$ (95\% CI, $0.325 \%$ to $5.673 \%$ ) (Figure 3).

Different lag patterns also affect cardiovascular mortality. In the cumulative lag study, we found both lag01 (the moving average for the past 48 hours) and lag04 (the moving average for the past 120 hours) have a significant effect. For lag01, every 100-point increase will bring about $4.026 \%$ (95\% CI, $1.516 \%$ to $6.536 \%$ ) increases in cardiovascular mortality. For lag04, every 100 -point increase will bring about $4.424 \%$ (95\% CI, $1.145 \%$ to $7.703 \%)$ increases in cardiovascular mortality. In a singleday lag pattern, we found statistically significant differences in lag1 and lag3 (Table 2).

The overall results are consistent with the sensitivity analysis, indicating that the results are accurate.

\section{Discussion}

To our best knowledge, this study is the first one ever to investigate the relationship between stock volatility and cardiovascular mortality. We concluded that stock fluctuation has a significant and positive relationship with 
Table 1 Characteristics of included studies

\begin{tabular}{|c|c|c|c|c|c|c|c|c|}
\hline $\begin{array}{l}\text { Authors } \\
\text { and year of } \\
\text { publication }\end{array}$ & $\begin{array}{c}\text { Outcomes } \\
\text { investigated }\end{array}$ & $\begin{array}{l}\text { Published } \\
\text { journal }\end{array}$ & $\begin{array}{l}\text { Location and } \\
\text { period of data } \\
\text { obtained }\end{array}$ & $\begin{array}{l}\text { Study } \\
\text { design }\end{array}$ & Model & $\begin{array}{c}\text { No. } \\
\text { events }\end{array}$ & $\begin{array}{l}\text { Variables } \\
\text { controlled }\end{array}$ & $\begin{array}{c}\text { Lags } \\
\text { (single/ } \\
\text { average/ } \\
\text { both) }\end{array}$ \\
\hline $\begin{array}{l}\text { Ma et al., } \\
2011\end{array}$ & CHD mortality & $\begin{array}{l}\text { European Heart } \\
\text { Journal }\end{array}$ & $\begin{array}{l}\text { China, } \\
\text { Shanghai, } \\
\text { 2006-2008 }\end{array}$ & $\begin{array}{l}\text { Time- } \\
\text { series }\end{array}$ & $\begin{array}{l}\text { Over- } \\
\text { dispersed } \\
\text { generalized } \\
\text { linear Poisson } \\
\text { models }\end{array}$ & 22,272 & $\begin{array}{l}\text { Long-term } \\
\text { and seasonal } \\
\text { trends, } \\
\text { temperature, } \\
\text { relative } \\
\text { humidity, } \\
\text { PM10, and O3 } \\
\text { concentrations }\end{array}$ & Both \\
\hline $\begin{array}{l}\text { Yap et al., } \\
2016\end{array}$ & $\begin{array}{l}\text { Overall } \\
\text { mortality, } \\
\text { cardiovascular } \\
\text { mortality, } \\
\text { incident MI, } \\
\text { stroke, HF }\end{array}$ & $\begin{array}{l}\text { International } \\
\text { Journal of } \\
\text { Cardiology }\end{array}$ & $\begin{array}{l}\text { Singapore, } \\
2001-2012\end{array}$ & $\begin{array}{l}\text { Time- } \\
\text { series }\end{array}$ & $\begin{array}{l}\text { Generalized } \\
\text { linear model }\end{array}$ & $\mathrm{Na}$ & $\begin{array}{l}\text { Air pollutant } \\
\text { levels }\end{array}$ & NA \\
\hline $\begin{array}{l}\text { Zhang } \\
\text { et al., } 2013\end{array}$ & Stroke deaths & $\begin{array}{l}\text { Journal of } \\
\text { Cardiovascular } \\
\text { Medicine }\end{array}$ & $\begin{array}{l}\text { Nine urban } \\
\text { districts of } \\
\text { Shanghai, } \\
\text { 2006-2008 }\end{array}$ & $\begin{array}{l}\text { Time- } \\
\text { series }\end{array}$ & $\begin{array}{l}\text { Generalized } \\
\text { linear model }\end{array}$ & 29,566 & $\begin{array}{l}\text { Air pollutant } \\
\text { levels, day } \\
\text { of the week, } \\
\text { temperature, } \\
\text { humidity }\end{array}$ & Both \\
\hline $\begin{array}{l}\text { Lin et al., } \\
2013\end{array}$ & $\begin{array}{l}\text { Cardiovascular } \\
\text { mortality }\end{array}$ & PLoS One & $\begin{array}{l}\text { Taishan and } \\
\text { Guangzhou, } \\
\text { 2006-2010 }\end{array}$ & $\begin{array}{l}\text { Time- } \\
\text { series }\end{array}$ & $\begin{array}{l}\text { Generalized } \\
\text { linear } \\
\text { model and } \\
\text { distributed } \\
\text { lag non-linear } \\
\text { model }\end{array}$ & 41,085 & $\begin{array}{l}\text { Public } \\
\text { holidays, day } \\
\text { of the week, } \\
\text { temperature, } \\
\text { humidity, air } \\
\text { pollutant levels }\end{array}$ & Both \\
\hline
\end{tabular}

Study
Taishan
Guangzhou
Shanghai
Singapore
Overall (I-squared $=26 \%, \mathrm{p}=0.256)$
NOTE: Weights are from random effects analysis

Figure 2 Forrest plots: relationship between stock volatility and cardiovascular mortality. The result from Shanghai is the pooled estimates from 2 studies. 
$\begin{array}{ll}\text { Study } & \text { PC }(95 \% \mathrm{CI}) \quad \text { Weight }\end{array}$

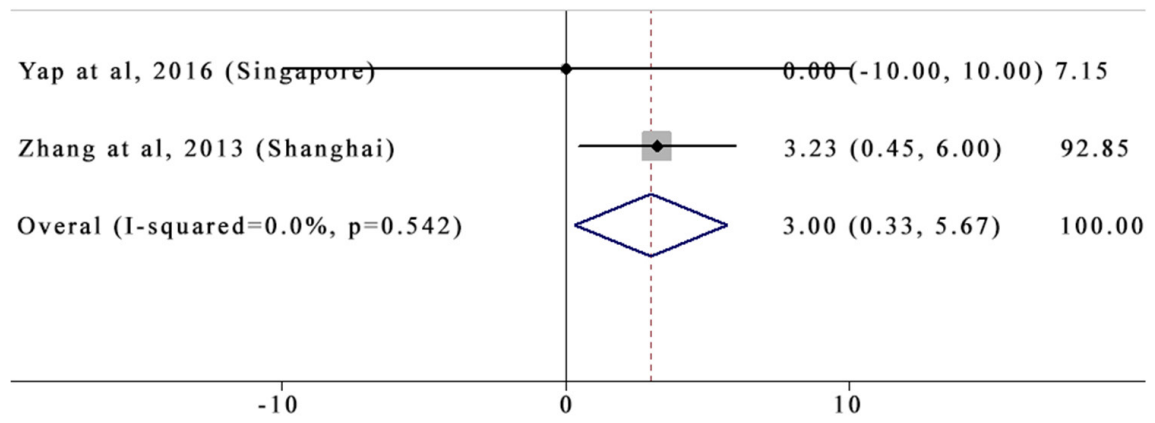

Figure 3 Forrest plots: relationship between stock volatility and stroke events.

Table 2 Relationship between stock volatility and cardiovascular disease mortality: Lag patterns

\begin{tabular}{lcccccc}
\hline Subtypes & Lag 01 & Lag 04 & Lag 1 & Lag 2 & Lag 3 & 2 \\
\hline Number of estimated articles & 2 & 2 & 2 & 2 & 2 & 3.775 \\
Effect size, \% (95\% Cl) & 4.026 & 4.424 & 2.425 & 0.061 & 1.018 \\
& $(1.516$ to 6.536$)$ & $(1.145$ to 7.703$)$ & $(0.11$ to 4.74$)$ & $(-2.726$ to 2.848) & $(1.018$ to 6.532) (-1.823 to 3.859) \\
Heterogeneity, I ${ }^{2}, \%$ & 0 & 0 & 77.2 & 16 & 0 & 0 \\
Model & Fixed & Fixed & Random & Fixed & Fixed & Fixed \\
\hline
\end{tabular}

cardiovascular mortality, especially cumulative change. The stroke event could also be influenced. There are no publication biases; therefore, the conclusion is dependable.

With the booming economy in the early 2000s, many individuals began to invest in the stock market worldwide. According to China Securities Depository and Clearing Corporation Statistical Yearbook 2018, the number of stock trading accounts jumped from 8.4 million in 1993 to 146.5 million in 2018, a 15 -fold increase in 25 years (http://www.chinaclear.cn/zdjs/tjnb/center_datalist. shtml). After 2007, an exceptional year in the stock market, China attracted many new investors. Unfortunately, several investors were inexperienced and with unrealistic expectations. Moreover, many of them were elderly who had time to watch the real-time performance of the stock market in the Stock Exchange Hall (14). The sharp change in the stock market will bring emotional or physical stress.

In our study, a positive relationship was found between stock volatility and stroke events. According to the global burden of disease held in 2017, stroke was listed as the second leading cause of death and disability around the world (15). In 2017, there were 11.9 million incidences and 104.2 million prevalence. The unrealistic individual investors with high expectations could not adapt to the dramatic changes in the stock market, depression and stress would also push them to stroke $(16,17)$. As the number of studies is small, we cannot conduct sensitivity analysis. However, earlier studies concluded that the stock index had more substantial effects on the male and elderly population, especially for those over the age of 65 (18). A loss impacted larger than a rise. This result is reasonable because, first, age itself is a risk factor for stroke.

Moreover, the elderly have more chronic diseases than younger ones. If stock volatility does have significant influences on stroke events, the elderly are most affected. Second, the elderly are always retired and have no income. If the stock market performs poorly, they may get more stress and depression, increasing the incidence of stroke (19). In terms of gender, it has been shown that daily change effects are significant only for males. The potential reason is men traded $45 \%$ more than women (12). Moreover, estrogen plays an essential part in the vasoconstriction in both superficial and deep arteries, protecting females from CVDs (20).

In our study, we concluded that both single and 
cumulate lag patterns affect CVD mortality. In terms of the effect value, lag04 has more effect than lag01 in the cumulative lag pattern. That is to say, the 120-hour moving average of stock market fluctuations influenced more than the 48-hour moving average. The timing of evaluating cardiovascular events after the stressor might be significant, and varying results have been observed. For example, one of the researchers concluded that a 10-day lag pattern had a stronger correlation with increased cardiovascular mortality (12). Earlier studies have shown different lag patterns for different stressrelated mortality and morbidity (21). Also, the short-term effect of the Northridge earthquake lasted for six days. The Los Angeles Northridge earthquake limited the duration of increased cardiovascular deaths to a few days (22). However, it influenced the Hanshin-Awaji earthquake, and the Athens earthquake persisted for 1 month $(23,24)$. Moreover, research on cardiovascular hospital admissions after the September 11 attacks showed no difference in 1 week after the attacks $(25,26)$. As different events have different lag patterns, more studies are needed to understand the structure of the stock market volatility further on cardiovascular health.

It has been estimated that psychological stress could sharply increase cardiovascular mortality and recurrent ongoing major cardiovascular events, including acute myocardial infarction (AMI) and stroke $(16,27)$. For example, after the US 911 terrorist attack, the CVD incidence rate increased by $53 \%$ and lasted for about 3 years (28). The same phenomenon could be observed after the Wenchuan earthquake in China, 2008 (29). The stock market all over the world underwent unprecedented fluctuations in recent years, which might lead to stress. Stress contributes not only to the acute triggering of cardiac events but also to the long-term development of CHD. Mechanisms, including sympathetic nervous system activation and increased abdominal fat deposition, account for it (30). Sharp fluctuation might also lead to depression, which has been listed as one of the high-risk factors for CVDs $(31,32)$.

We found that heterogeneity exists in our study. Heterogeneity came from inherent differences between the studies, as well as their design and statistical analysis. Except for the study areas and population, the outcome that we focused on might play a key role. Different regions had different economic characteristics; thus, the impact of stock varied. Other factors, including the study period, might take part as well. Heterogeneity can also appear when research results depend not solely on the quality of the research but also the hypothesis evaluated, and the significance and direction of effects detected (33).

Notable points in this work must be considered. First, even if we took all the published work into our analysis, various studies and places stopped us from further analysis. Many of our sensitivity analysis only includes two articles for many studies, which may not reflect the conditions of the whole population; we just want to get a trend out of this study and guide future research. Furthermore, more work should be conducted to confirm the susceptibility of the population. Second, some studies offer effect estimates not only from the absolute change of the stock market but also from the bidirectional change. They held the opinion that a rise in the stock market has a different effect on health than a fall. We do not consider the latter one because the design and statistical analysis vary widely. As the number of studies increases, a meta-analysis on bidirectional change may be conducted. Third, the limited number of published works also stopped us from further testing the publication bias, which came from the tendency on the parts of investigators, reviewers, and editors to submit or accept manuscripts for publication with the direction or strength of the study findings (34). As more studies appear, a new meta-analysis will solve the problem. Last, potential confounding factors such as influenza should be considered in the included articles because it may have a great impact on economic development. Thus, more research is needed.

Our study supplied further evidence that stock volatility might increase CVD mortality in Shanghai, China. Shanghai is the economic center of China. The number of investors in Shanghai is ten times the national average (http://www.chinaclear.cn/zdjs/tjnb/center_datalist.shtml). More attention to the stock market causes more stress and mood changes, which lead to changes in the number of illnesses. That may amplify the estimated effect. Further studies should be taken in other places in China and other parts of the world.

\section{Conclusions}

Our study suggested that changes in the stock market have a lag effect on CVD mortality. It may last for several days. Also, it may increase the incidence of stroke events. Although a limited number of articles stopped us from further analysis, we want to remind investors to invest cautiously to avoid cardiovascular events caused by stress and pressure. 


\section{Acknowledgments}

Funding: This work was supported by the Basic Scientific Research Business Fee of Central Public Welfare Research Institute, China (2016ZX310181-4).

\section{Footnote}

Reporting Checklist: The authors have completed the PRISMA reporting checklist. Available at http://dx.doi. org/10.21037/atm-20-6557

Conflicts of Interest: All authors have completed the ICMJE uniform disclosure form (available at http://dx.doi. org/10.21037/atm-20-6557). The authors have no conflicts of interest to declare.

Ethical Statement: The authors are accountable for all aspects of the work in ensuring that questions related to the accuracy or integrity of any part of the work are appropriately investigated and resolved.

Open Access Statement: This is an Open Access article distributed in accordance with the Creative Commons Attribution-NonCommercial-NoDerivs 4.0 International License (CC BY-NC-ND 4.0), which permits the noncommercial replication and distribution of the article with the strict proviso that no changes or edits are made and the original work is properly cited (including links to both the formal publication through the relevant DOI and the license). See: https://creativecommons.org/licenses/by-nc-nd/4.0/.

\section{References}

1. Truelsen T, Krarup LH, Iversen HK, et al. Causes of Death Data in the Global Burden of Disease Estimates for Ischemic and Hemorrhagic Stroke. Neuroepidemiology 2015;45:152-60.

2. Ferdinand KC. Global perspectives on cardiometabolic risk and cardiovascular disease: from basic science to bedside. Ann Transl Med 2018;6:290.

3. Mensah GA, Roth GA, Sampson UK, et al. Mortality from cardiovascular diseases in sub-Saharan Africa, 1990-2013: a systematic analysis of data from the Global Burden of Disease Study 2013. Cardiovasc J Afr 2015;26:S6-10.

4. Ladwig KH, Lederbogen F, Albus C, et al. Position paper on the importance of psychosocial factors in cardiology: Update 2013. Ger Med Sci 2014;12:Doc09.
5. Ma W, Chen H, Jiang L, et al. Stock volatility as a risk factor for coronary heart disease death. Eur Heart J 2011;32:1006-11.

6. Moher D, Liberati A, Tetzlaff J, et al. Preferred reporting items for systematic reviews and meta-analyses: the PRISMA statement. Int J Surg 2010;8:336-41.

7. Chen ZB, Fan LB, Liu YJ, et al. Meta-Analysis of the Effects of Cardiac Rehabilitation on Exercise Tolerance and Cardiac Function in Heart Failure Patients Undergoing Cardiac Resynchronization Therapy. Biomed Res Int 2019;2019:3202838.

8. Tseng AS, Kunze KL, Lee JZ, et al. Efficacy of Pharmacologic and Cardiac Implantable Electronic Device Therapies in Patients With Heart Failure and Reduced Ejection Fraction: A Systematic Review and Network Meta-Analysis. Circ Arrhythm Electrophysiol 2019;12:e6951.

9. Song W, Ma W, Kan H. Stock Volatility and Deaths From Heart Disease and Stroke in a Chinese Population. Epidemiology 2011;22:S180.

10. Schwartz BG, Pezzullo JC, McDonald SA, et al. How the 2008 stock market crash and seasons affect total and cardiac deaths in Los Angeles County. Am J Cardiol 2012;109:1445-8.

11. Fiuzat M, Shaw LK, Thomas L, et al. United States stock market performance and acute myocardial infarction rates in 2008-2009 (from the Duke Databank for Cardiovascular Disease). Am J Cardiol 2010;106:1545-9.

12. Chen CC, Chen CS, Liu TC, et al. Stock or stroke? Stock market movement and stroke incidence in Taiwan. Soc Sci Med 2012;75:1974-80.

13. Zhang $Y$, Wang $X, X u X$, et al. Stock volatility and stroke mortality in a Chinese population. J Cardiovasc Med (Hagerstown) 2013;14:617-21.

14. Lin H, Zhang Y, Xu Y, et al. Large Daily Stock Variation Is Associated with Cardiovascular Mortality in Two Cities of Guangdong, China. PLoS One 2013;8:e68417.

15. Yap J, Earnest A, Lee V, et al. Impact of stock market volatility on mortality and cardiovascular events. Int J Cardiol 2016;223:318-9.

16. Chen G, Kim KA, Nofsinger JR, et al. Behavior and performance of emerging market investors: Evidence from China. China International Financial Conference Proceedings 2006:1-36.

17. Krishnamurthi RV, Ikeda T, Feigin VL. Global, Regional and Country-Specific Burden of Ischaemic Stroke, Intracerebral Haemorrhage and Subarachnoid Haemorrhage: A Systematic Analysis of the Global Burden 
of Disease Study 2017. Neuroepidemiology 2020;54:171-9.

18. Tsutsumi A, Kayaba K, Kario K, et al. Prospective study on occupational stress and risk of stroke. Arch Intern Med 2009;169:56-61.

19. Chandola T, Britton A, Brunner E, et al. Work stress and coronary heart disease: what are the mechanisms? Eur Heart J 2008;29:640-8.

20. Jackson CA, Kerssens J, Fleetwood K, et al. Incidence of ischaemic heart disease and stroke among people with psychiatric disorders: retrospective cohort study. Br J Psychiatry 2020;217:442-9.

21. Barber BM, Odean T. Boys will be Boys: Gender, Overconfidence, and Common Stock Investment. Q J Econ 2001;116:262-92.

22. Sato F, Matsushita S, Hyodo K, et al. Sex difference in peripheral arterial response to cold exposure. Circ J 2008;72:1367-72.

23. Steptoe A, Kivimaki M. Stress and cardiovascular disease: an update on current knowledge. Annu Rev Public Health 2013;34:337-54.

24. Dobson AJ, Alexander HM, Malcolm JA, et al Heart attacks and the Newcastle earthquake. Med J Aust 1991;155:757-61.

25. Trichopoulos D, Katsouyanni K, Zavitsanos X, et al. Psychological stress and fatal heart attack: the Athens (1981) earthquake natural experiment. Lancet 1983;1:441-4.

26. Kario K. Does earthquake-induced cardiovascular disease persist or is it suppressed after the major quake? J Am Coll Cardiol 1998;32:553-4.

Cite this article as: Lian $\mathrm{H}$, Ding $\mathrm{X}$, Zhang $\mathrm{H}$, Wang $X$. Short-term effect of stock volatility and cardiovascular mortality: a systematic review and meta-analysis. Ann Transl Med 2020;8(20):1317. doi: 10.21037/atm-20-6557
27. Allegra JR, Mostashari F, Rothman J, et al. Cardiac events in New Jersey after the September 11, 2001, terrorist attack. J Urban Health 2005;82:358-63.

28. Chi JS, Speakman MT, Poole WK, et al. Hospital admissions for cardiac events in New York City after September 11, 2001. Am J Cardiol 2003;92:61-3.

29. Musey PI, Schultebraucks K, Chang BP. Stressing Out About the Heart: A Narrative Review of the Role of Psychological Stress in Acute Cardiovascular Events. Acad Emerg Med 2020;27:71-9.

30. Holman EA, Silver RC, Poulin M, et al. Terrorism, acute stress, and cardiovascular health: a 3-year national study following the September 11th attacks. Arch Gen Psychiatry 2008;65:73-80.

31. Huang K, Deng X, He D, et al. Prognostic implication of earthquake-related loss and depressive symptoms in patients with heart failure following the 2008 earthquake in Sichuan. Clin Cardiol 2011;34:755-60.

32. Hare DL, Toukhsati SR, Johansson P, et al. Depression and cardiovascular disease: a clinical review. Eur Heart J 2014;35:1365-72.

33. Kaplan JR, Chen H, Manuck SB. The relationship between social status and atherosclerosis in male and female monkeys as revealed by meta-analysis. Am J Primatol 2009;71:732-741.

34. Dickersin K. The existence of publication bias and risk factors for its occurrence. JAMA 1990;263:1385-9.

(English Language Editor: J. Chapnick) 